Florida International University FIU Digital Commons

FIU Electronic Theses and Dissertations

University Graduate School

2-6-2012

\title{
Evaluating Heavy Episodic Drinking Effects on Educational Attainment.
}

Tracey A. Garcia

Florida International University, traceygarcia77@gmail.com

DOI: $10.25148 /$ etd.FI12042319

Follow this and additional works at: https://digitalcommons.fiu.edu/etd

\section{Recommended Citation}

Garcia, Tracey A., "Evaluating Heavy Episodic Drinking Effects on Educational Attainment." (2012). FIU Electronic Theses and Dissertations. 583.

https://digitalcommons.fiu.edu/etd/583

This work is brought to you for free and open access by the University Graduate School at FIU Digital Commons. It has been accepted for inclusion in FIU Electronic Theses and Dissertations by an authorized administrator of FIU Digital Commons. For more information, please contact dcc@fiu.edu. 


\section{FLORIDA INTERNATIONAL UNIVERSITY \\ Miami, Florida}

EVALUATING HEAVY EPISODIC DRINKING EFFECTS ON EDUCATIONAL

ATTAINMENT

A dissertation submitted in partial fulfillment of the

requirements for the degree of

DOCTOR OF PHILOSOPHY

in

PSYCHOLOGY

by

Tracey Anne Garcia

2012 
To: Dean Kenneth G. Furton

College of Arts and Sciences

This dissertation, written by Tracey Anne Garcia, and entitled Evaluating Heavy Episodic Drinking Effects on Educational Attainment, having been approved in respect to style and intellectual content, is referred to you for judgment.

We have read this dissertation and recommend that it be approved.

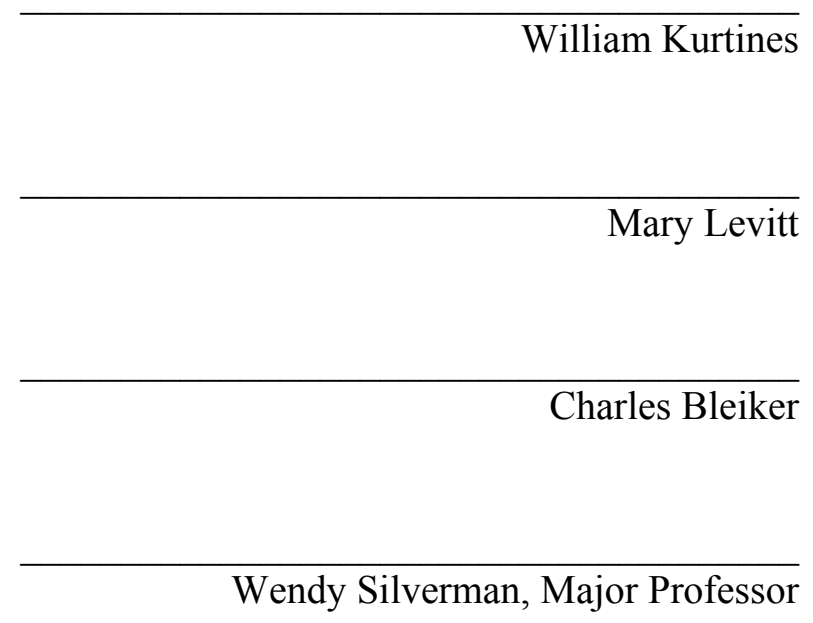

Date of Defense: February 6, 2012

The dissertation of Tracey Anne Garcia is approved.

$\begin{array}{r}\text { Dean Kenneth G. Furton } \\ \text { College of Arts and Sciences } \\ \hline \begin{array}{r}\text { Dean Lakshmi N. Reddi } \\ \text { University Graduate School }\end{array}\end{array}$

Florida International University, 2012 


\section{ABSTRACT OF THE DISSERTATION \\ EVALUATING HEAVY EPISODIC DRINKING EFFECTS ON EDUCATIONAL ATTAINMENT \\ by \\ Tracey Anne Garcia}

Florida International University, 2012

Miami, Florida

\section{Professor Wendy K. Silverman, Major Professor}

Adolescence and emerging adulthood are transition points that offer both opportunities and constraints on individual development. The purpose of this study is threefold: First, to examine two models (i.e., young adolescents in grades 7 and 8 and older adolescents in grade 12) of heavy episodic drinking and examine how heavy episodic drinking affects subsequent educational attainment. By utilizing two different developmental transitions, i.e., middle school to high school and high school to college, it may be possible to better understand the temporal effects of alcohol use and subsequent educational attainment. The second purpose of this study is to examine how alcohol use at Time 1 may lead to the problems in the adolescent's immediate context due to alcohol (i.e., problems with parents, peers, romantic relationships, problems at school) and to examine if these problems affect educational attainment over and above alcohol use alone. The third purpose of this study is to examine the potential gender differences in these models. The study uses data from the National Longitudinal Study of Adolescent Health, which is a large scale, nationally representative school based sample of 20,745 adolescents who were interviewed in grades 7 to 12 . Two longitudinal mediational models were evaluated 
utilizing structural equation modeling. Binge drinking and number of days drunk were used as indicators for a latent variable of heavy episodic drinking (i.e., LHED). In the $7^{\text {th }}$ and $8^{\text {th }}$ grade model, direct effects of LHED were found to predict educational attainment at grade 12 . Additionally, in the $7^{\text {th }}$ and $8^{\text {th }}$ grade sample, a mediated relationship was found whereby educational attainment was predicted by problems with parents. Problems with parents were predicted by number of days drunk in the past year. In the $12^{\text {th }}$ grade sample, there were no direct effects or indirect effects of alcohol on educational attainment. This study highlights the need for using a longitudinal framework when examining heavy episodic drinking's effects on educational attainment. 


\section{TABLE OF CONTENTS}

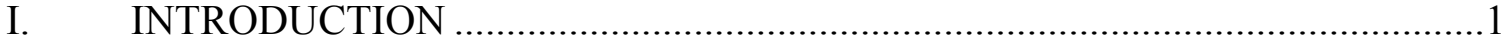

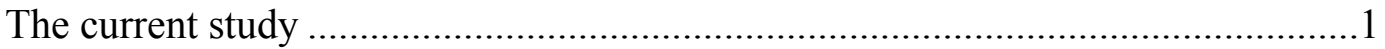

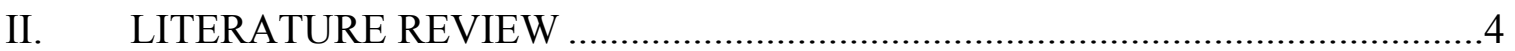

Middle school, alcohol use, and educational attainment ..................................

Prevalence of alcohol use in middle school ........................................................

Middle school alcohol use and completion of high school...................................4

Theoretical model for 7 th and 8 th graders .......................................................6

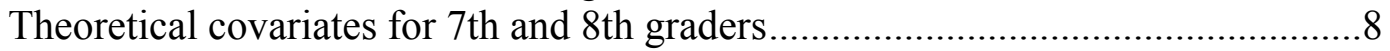

Addressing the transition between high school and young adulthood.................... 8

Prevalence of alcohol use in late high school ..................................................

Past research investigating alcohol use and educational attainment in college .......9

Theoretical model of late high school..............................................................11

Theoretical covariates for late high school ...................................................11

Gender differences in heavy episodic drinking and educational attainment .........12

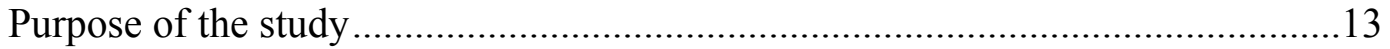

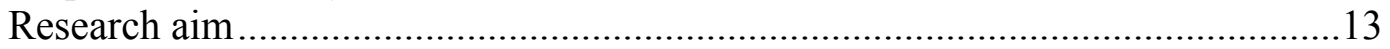

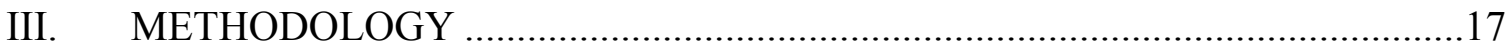

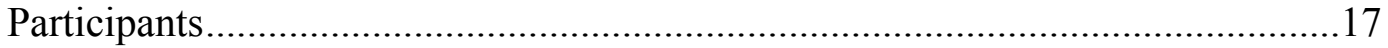

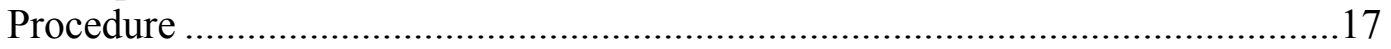

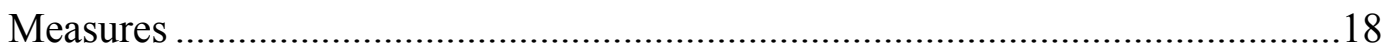

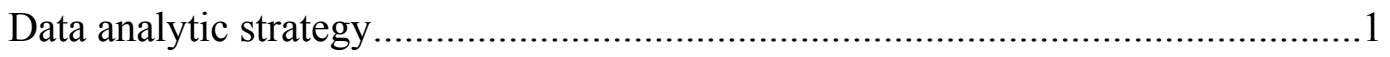

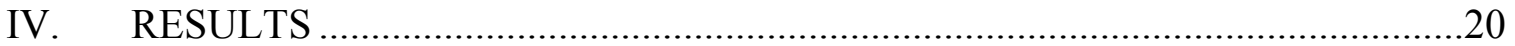

7th and 8th grade model mediation and outcomes...........................................22

12th grade model mediation and outcomes ..................................................23

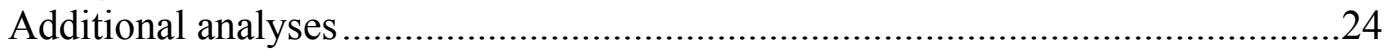

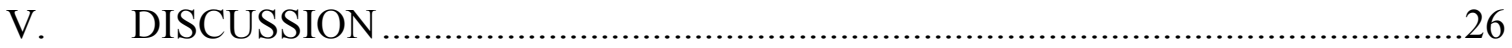

Middle school alcohol use and completion of high school...............................26

12th grade alcohol use and college educational attainment.................................30

Limitations and directions for future research .................................................33

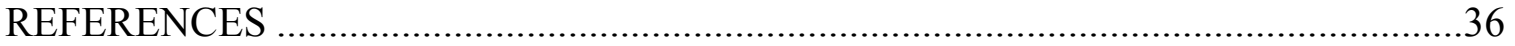

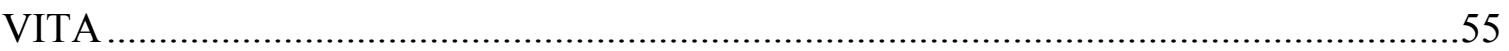




\section{LIST OF TABLES}

TABLE

PAGE

1. Summary of Age, Ethnicity, and Study Variables for the Seventh and Eighth graders

2. Summary of Age, Ethnicity, and Study Variables for $12^{\text {th }}$ Graders....

3. Summary of Study Variables for Seventh and Eighth Graders: Wave 1......45

4. Summary of Study Variables for $12^{\text {th }}$ Graders: Wave $1 \ldots \ldots \ldots \ldots \ldots \ldots . . . . .46$

5. Model Path Coefficients for Seventh and Eighth Graders.................47

6. Model Path Coefficients for $12^{\text {th }}$ Graders.............................48

7. Summary of Drinking Variables for $7^{\text {th }}$ and $8^{\text {th }}$ Graders....................49

8. Summary of Drinking Variables for $12^{\text {th }}$ Graders........................50 


\section{INTRODUCTION}

During childhood and adolescence, there are many rapid changes in form, status, and function within the individual (Masten, Faden, Zucker, \& Spear, 2008). Further, new contextual shifts from childhood to adolescence and from adolescence to young adulthood make these dramatic periods of change and adjustment or maladjustment in the life course. During these times of instability and rapid change, points of vulnerability and opportunity for developing a different life course are possible (Masten et al., 2008).

Developmentally, the change of context between middle school, high school, and college coincides with new role adaptations. These periods can be thought of as unstable points where rapid change occurs within and outside of the person. When these transitions occur, vulnerabilities or opportunities are prevalent (Masten et al., 2008). At different transition points, there may be possibilities of continuity of alcohol use or discontinuity of alcohol use. Distal effects can impact long term alcohol use or may become reduced or reversed depending on the proximal effects (Schulenburg \& Maggs, 2008). An important component of examining alcohol consumption from a developmental psychopathological framework is to consider timing of events. Many predictors and outcomes are impacted by time, such that some problem behaviors become normative at some points in life (e.g., heavy episodic drinking at 20) when compared to other times when problem behaviors are nonnormative (e.g., heavy episodic drinking at 13). Timing of alcohol use initiation and subsequent drinking has been investigated within the psychological literature, however, the research is equivocal, (e.g., York, 1995; Labouvie \& White, 1998). One possible venue to examine within alcohol consumption is to examine the nonnormative/unexpected and disapproved facet of alcohol use, 
specifically young adolescent binge drinking and frequency of times drunk. By

examining the nonnormative/unexpected alcohol use, meaningful patterns may develop in regards to possible problems across context and across time.

In addition to examining the nonnormative/unexpected alcohol use it is important to investigate transition into emerging adulthood (e.g., the transition between high school and college) as many individuals are now delaying adopting traditional adult roles and instead are continuing into college. Incidentally, there is still a proportion of the population who does not seek post high school education and are instead adopting tasks associated with adulthood. The differences between these groups have been examined within the literature, but most often not from the transition from high school on; most studies instead focus on the later college or the transition out of college.

\section{The Current Study}

Although adolescence and emerging adulthood is a time of many changes, what appears to be consistent across adolescence and young adulthood for many adolescents is a dangerous pattern of abusing alcohol by engaging in heavy episodic drinking. Alcohol is the drug of choice for many adolescents and emerging adults. Timing of alcohol use initiation and subsequent drinking has been investigated within the psychological literature; however, the research is equivocal in regards to timing of alcohol initiation, later alcohol use, and developmental outcomes, i.e., educational attainment; (e.g., York, 1995; Labouvie \& White, 1998). There have been a variety of outcomes studied in terms

of the impact of alcohol use in middle school and high school, but this study focuses on how educational attainment is affected by heavy episodic drinking using a longitudinal design in a nationally representative sample of adolescents. 
First, the existing literature will be reviewed on alcohol rates in middle school, the heavy episodic drinking/educational attainment relationship in middle school, and possible correlates/covariates that may affect educational attainment and heavy episodic drinking. Additionally, a model will be delineated (i.e., set of hypothesized relationships) that will clarify the heavy episodic drinking/educational attainment relationship. The focus is on predicting high school completion from alcohol use in middle school.

In addition, the current study aimed not only to understand the heavy episodic drinking/educational attainment relationship in middle school, but also to obtain an appreciation of this relationship during the transition between high school and college. Subsequently, drinking rates in late high school, i.e., $12^{\text {th }}$ grade, the literature that pertains to how heavy episodic drinking at this time predicts completion of college, and the literature on possible correlates of college educational attainment and heavy episodic drinking in high school seniors is also reviewed. The same model proposed for middle school youth was tested for high school seniors. 


\section{LITERATURE REVIEW}

\section{Middle School, alcohol use, and educational attainment}

Prevalence of alcohol use in middle school. Although there has been research examining alcohol use in high school and college, alcohol use begins earlier for many youth, during pre or early adolescence. Statistics from the Monitoring the Future survey (2006) demonstrate this trend in early alcohol use, with $39 \%$ of $8^{\text {th }}$ graders reporting alcohol use in their lifetime and $16 \%$ of $8^{\text {th }}$ graders being current (i.e., past 30 days) alcohol users. $53 \%$ of adolescents had initiated alcohol use by the end of the $9^{\text {th }}$ grade. (Johnson, O’Malley, Bachman, Schulenberg, 2008). Results from the MTF survey also shed light on another important facet of adolescent drinking-drunkenness (i.e., frequency of being drunk). $18 \%$ of $8^{\text {th }}$ graders have been drunk in their lifetime and $8 \%$ of $8^{\text {th }}$ graders have engaged in heavy episodic drinking, i.e., 5 or more drinks in a row, in the past two weeks.

Middle school alcohol use and the completion of high school. Little is known about how binge-drinking and alcohol use in middle school might be predictive of high school academic completion. However, research suggests that individuals who drop out of high school are more likely to live in poverty, be unemployed, in prison, unhealthy, and with children who often drop-out themselves (Bridgeland, 2006).

In a study that examined the relationship between binge drinking and educational attainment, Tucker, Ellickson, Orlando, Martino, and Klein (2005) examined a sample of 6,527 middle school students living in California and Oregon, (48\% female; 67\% white), participating in the RAND Adolescent/Young Adult Panel study. The study utilized latent growth mixture modeling to examine the 10 waves of data, collected at ages 13,14 , 
$15,16,18$, and 23 , and used this design to create trajectories for the different classes. Heavy episodic drinking in this study had two definitions: 1) past 30 day use of 3 or more drinks for adolescents between the ages of 13-16; and, 2) past 30 day use of 5 or more drinks at the time points of 18 and 23 . The study assessed a variety of behavioral outcomes at age 23, but pertinent to the proposed study, Tucker et al., (2005) examined whether participants had earned a college degree. Of the identified trajectories, individuals who were in the moderate stable trajectory (i.e., $54 \%$ of binge drinkers at age 13 who did not exceed one binge episode per month) had a lower likelihood of college graduation than adolescents who abstained from binge drinking. Interestingly, the trajectory of steady increasers, i.e., $23 \%$ of binge drinkers who had a low level of alcohol use at age 13 , but whose alcohol consumption increased steadily until age 23 , indicated that this class had the highest level of use by age 23 in binge drinking and they were no less likely to graduate from college than abstainers (Tucker et al., 2005). This study's significant findings may point to two potential vulnerable periods of heavy episodic use: one in early adolescence and one in late adolescence and emerging adulthood.

An important piece of information missing from Tucker et al., (2005) is whether the trajectories that predicted non-earned college degrees also predicted non-earned high school degrees. There was no information given about the effect of binge drinking in adolescence on high school educational attainment. The authors also controlled for demographics, but the potential gender differences were not examined.

Hair, Park, Ling, and Moore (2009) examined young adolescent (i.e., between the ages of 12 and 14) risk behaviors in the National Longitudinal Survey of Youth 1997 cohort $(\mathrm{n}=338 ; 50.79 \%$ male; $67.26 \%$ non-Hispanic white). The authors conducted a 
latent class analysis to determine risk profiles based on delinquency, smoking, drug use, drinking, sexual behavior, and exercise. This set of predictors yielded four risk groups including a low-risk group, $(\mathrm{n}=896)$; a high-risk group, $(\mathrm{n}=1100$, i.e., majority engaged in delinquency, smoking, drug use, drinking, unsafe sex, and were not likely to exercise); a drinking and unsafe sex moderate risk group, $(n=716$, i.e., higher percentages of adolescents engaging in unsafe sex, drinking, and exercise); and a smoking, unsafe sex, and lack of exercise moderate risk group $(n=1874$, higher percentages of smoking, unsafe sex, and not engaging in exercise). Multivariate analyses predicting outcomes at ages 17-19 revealed that the high-risk group was more likely to report mental health problems and lower levels of academic achievement, not having a high school diploma or GED, and were more likely to be White when compared to the low- risk group. When compared to the low-risk group, the high risk group was 1.8 times more likely to be unemployed or out of school, and three times more likely to drop out of school.

Interestingly, the high-risk group was comprised of more males than females and the group was also predominately white, non-Hispanic. Although interesting conclusions can be drawn from this study, it is hard to delineate how much of the drop-out rate was due to alcohol use without the other risk factors.

\section{Theoretical model investigating heavy episodic drinking in middle school and}

completion of high school. Although there is literature related to middle school alcohol use, research on heavy episodic drinking and its relationship to subsequent high school completion is sparse. The current study was conducted to advance understanding of how heavy episodic alcohol use may affect educational attainment in high school by utilizing a longitudinal framework whereby high school educational attainment is predicted by 
heavy episodic drinking in $7^{\text {th }}$ and $8^{\text {th }}$ grades. Figure 1 presents the working theoretical framework that guides the research.

Figure 1.

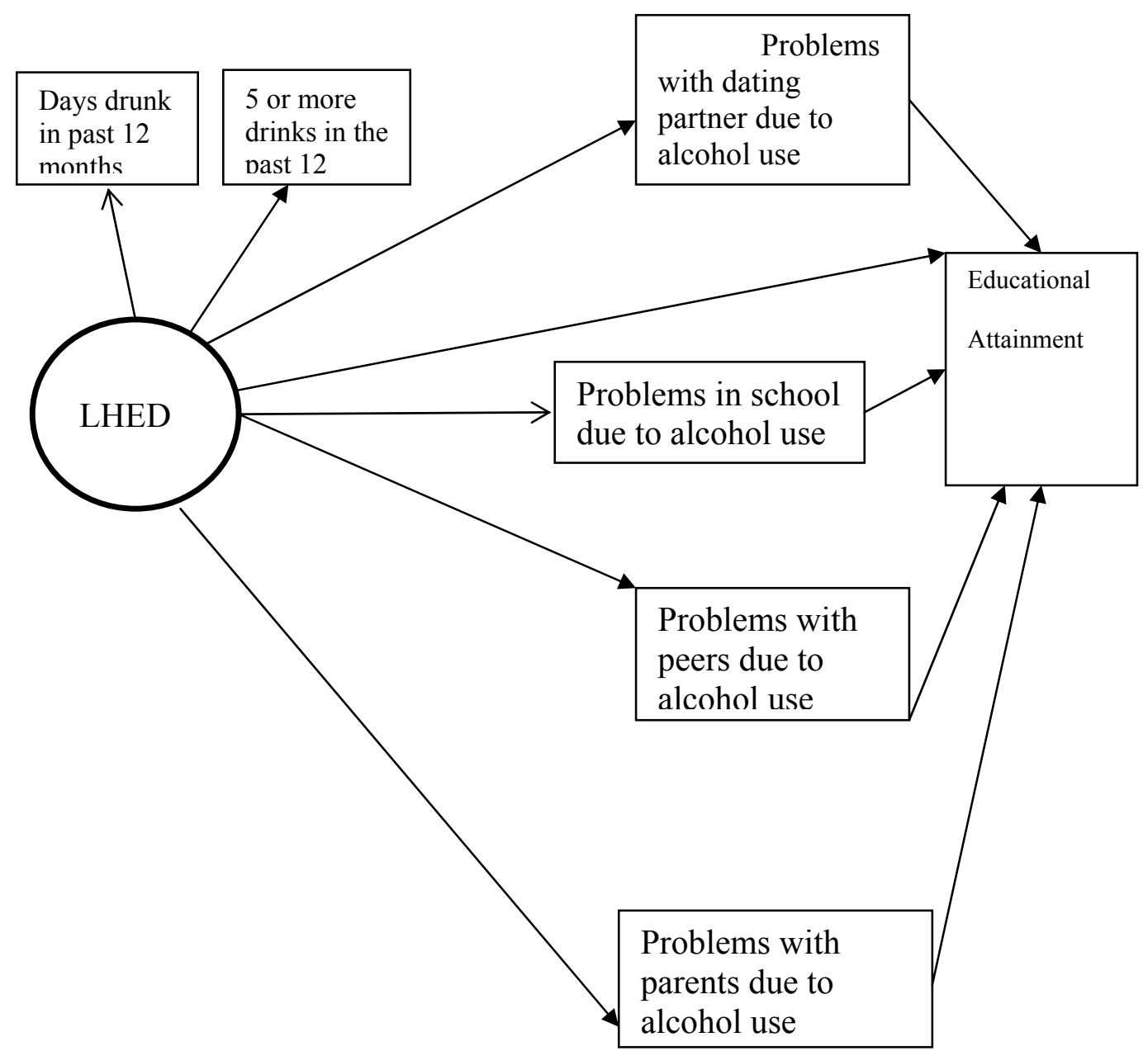

Partial mediation was explored by examining how alcohol consumption affects problems experienced in different context (e.g., problems with parents, friends, boyfriend/girlfriend, school, due to alcohol use). Given alcohol use has been linked to many such contextual problems in past research, this study sought to determine whether 
heavy episodic alcohol use predicted educational attainment over and above the contextual problems that are often associated with alcohol use (Delucchi, Matzger, \& Wesiner, 2008; Kessler, Foster, Saunders, \& Stang, 1995).

Theoretical covariates to alcohol and educational attainment. Literature relating to both alcohol use and educational attainment suggests a variety of variables that may impact both alcohol use and educational attainment and that may serve as confounds. It is therefore important to control for these variables in the analysis. These include variables related to school (e.g., G.P.A. and school connectedness; parental factors, educational attainment of parent and home structure; and adolescent individual difference variables, academic aspirations of the adolescent and ethnicity).

\section{Addressing the transition between high school and young adulthood, alcohol use, and college educational attainment}

Prevalence of alcohol use in late high school. The MTF study found $72 \%$ of $12^{\text {th }}$ graders have tried alcohol and $43 \%$ of $12^{\text {th }}$ graders have used alcohol in the past 30 days (Johnson et al., 2008). $37 \%$ of $10^{\text {th }}$ graders and $55 \%$ of $12^{\text {th }}$ graders have been drunk at least once in their lifetime. $16 \%$ of $10^{\text {th }}$ graders and $25 \%$ of $12^{\text {th }}$ graders have engaged in heavy episodic drinking (i.e., drank 5 or more drinks in a row) in the past two weeks. This pattern of drinking and being drunk seems to be more constant than merely experimental use with $16 \%$ of $10^{\text {th }}$ graders and $30 \%$ of $12^{\text {th }}$ graders, indicating they have used alcohol 20 or more times in their lifetime with $5 \%$, and $17 \%$ of those adolescents, grades respective, indicating that they were drunk on more than 20 occasions. Alcohol use also tends to be more stable in usage from the time of first tried, $72 \%$ of $12^{\text {th }}$ graders, throughout the senior year, $66 \%$ of those $12^{\text {th }}$ graders continued to use alcohol. 
Although heavy episodic drinking in the transition between high school and college is generally accepted by peers (Deas \& Clark, 2009), there are still negative consequences identified with it (e.g., sexual assault, drunken driving, risky behaviors) in older adolescence and emerging adulthood (Ham \& Hope, 2005). The transition between high school and college engenders feelings of acceptance of alcohol use in a college environment. Many studies indicate success in school is negatively related to substance use (e.g., Hawkins, Catalano, \& Miller, 1992; Kandel, 1990; Newcomb \& Bentler, 1986). There have been few studies that examine high school heavy episodic drinking among adolescents who eventually attend college as a predictor of completion of college and attainment of a college degree. The present study does so.

\section{Past research investigating alcohol use and educational attainment in college}

populations. Lanza and Collins (2006) examined patterns of heavy drinking over time using a latent class analysis design. The authors utilized a nationally representative sample $(\mathrm{n}=1265)$ that was sampled at ages $18,19,20,24,25$ and 30 . The authors assessed whether the participants were in college at either age 19 or 20 , of which $33.1 \%$ of the sample was enrolled in college compared to $62.4 \%$ of the sample not currently enrolled in college. Heavy drinking, i.e. alcohol use, was measured by an ordinal variable indicating the frequency of the participant drinking 6 or more drinks at one time in the past month (Lanza \& Collins, 2006). The authors identified 8 latent classes in the sample, i.e., lifetime heavy drinking, $16.9 \%$; no heavy drinking, $53.7 \%$; increasing trend, $12.4 \%$; decreasing trend, $10.7 \%$; short-term, $6.3 \%$. Interestingly, individuals who were not enrolled in college were almost three times more likely than those who were enrolled in college to commence heavy drinking in young adulthood $(p=.09$; Lanza \& Collins, 
2006). The authors also found that there were no significant differences between collegeenrolled individuals and non-college attending peers when examining the probability of engaging in heavy drinking in adulthood given that one engaged in this behavior in high school, although heavy drinking does occur and sometimes does begin in the college years. This study highlights what other studies have also found: it is more likely for drinking to begin in high school than in college. In this study, it was two to three times more likely to begin drinking in high school, Lanza \& Collins, 2006.

Another study examining how academic problems may be affected by alcohol use was conducted by Wood, Sher, Erickson, \& DeBord (1994). Wood et al. conducted their longitudinal study in a large Midwestern university with 489 incoming first-time freshmen, 252 at-risk students, and 257 women. The researchers then assessed academic problems (i.e., GPA, percent of academic terms on probation, bachelor's degree obtained, and number of academic terms ineligible) and alcohol involvement (i.e., negative alcohol consequences, alcohol dependence symptoms in the past year, mean frequency/quantity based on month and year, abuse or dependence diagnoses based on DSM-III, heavy drinking composite). They also assessed drug involvement, general deviance, and academic aptitude. Wood et al. found that there was a moderate, significant association between freshman alcohol consumption and cumulative academic problems. However, when the authors added gender, mother's alcohol use, father's alcohol use, mother's depression, father's depression, mother's education, father's education, high school class rank, campus involvement, and academic investment, the contribution of alcohol to academic outcomes decreased radically (i.e., unique contribution of variance went from 
$10 \%$ to $.01 \%$ ). This study's findings challenge therefore the general assumption that alcohol use negatively impacts educational attainment.

There are many studies examining college heavy episodic drinking (e.g.,Slutske 2005; Slutske 2004; Martinez, Sher, \& Wood, 200). Lanza and Collin (2006), as well as other studies (e.g. Masten et al., 2008), pointing to the need for targeted interventions and a more nuanced understanding of developmental trajectories and pathways which reverberate back to high school or earlier. Many college attending individuals "mature out" of problematic drinking, but not all do (Schlunberg, Bachman, O'Malley, \& Johnston, 1994; Zucker, 1987). It is therefore important to include college educational attainment as an outcome as some individuals may have heavy drinking patterns upon entering college and then subsequently do not complete college. Understanding the effects of alcohol use in high school or earlier and the subsequent transition into college will shed light on these disparities within research.

\section{Theoretical model of late high school heavy episodic drinking and college}

educational attainment. In the current study, it was examined whether $12^{\text {th }}$ grade heavy episodic drinking is related to attending a four year university or graduate school as mediated by contextual problems. The same model as presented in Figure 1 was evaluated for students who were enrolled in college. Measures of alcohol use during the senior year of high school were used to predict whether the student is attending or has attended a four year college or graduate school five years later.

Theoretical covariates in alcohol use and educational attainment. As in the previous model with middle school drinking, there are personal student variables (e.g., ethnicity, educational aspirations; educational attainment, , school connectedness, and 
students' GPA) and parental variables (e.g., educational aspirations for children; parental factors, educational attainment) that may confound the relationship between alcohol use and educational attainment. These factors were treated as covariates.

\section{Gender differences in heavy episodic drinking and educational attainment}

Another area that is garnering attention among alcohol researchers is the potential gender differences in initiation and subsequent alcohol use. Specifically, the prevalence estimates for alcohol use in adolescence and emerging adulthood for men and women are becoming more similar than dissimilar (e.g., Center for Disease Control and Prevention, 2006; Ham \& Hope, 2003; Johnston et al., 2008). Despite the similarities that are emerging, many studies examining alcohol use, abuse, and dependence in adulthood point to males having more problems with alcohol than females, (e.g., Clements, 1999; O’Malley \& Johnson, 2002; Substance Abuse and Mental Health Services Administration, 2008). However, when examining binge drinking among adolescents, the rates converge. For example, in the MTF survey (Johnson, et al., 2008) there were negligible differences between males and females in binge drinking in the $8^{\text {th }}$ grade (i.e., $10.4 \%$ versus $10.0 \%$ ). Also, the gender gap in binge drinking among college students has been closing and may be characteristic of an increase in female binge drinking and a decrease in male binge drinking (Johnson et al., 2008). Considering possible gender differences in alcohol use is an important part of a model. Given the recent research findings in regards to possible gender effects, the present research tested whether any of the structural coefficients in Figure 1 varied as a function of gender. 


\section{Purpose of the Study}

The purpose of this study was to examine two models of heavy episodic drinking and subsequent educational attainment, in which the variables were examined separately for $7^{\text {th }} / 8^{\text {th }}$ graders and $12^{\text {th }}$ graders. By using two different developmental transitions ( i.e., middle school to high school and high school to college completion) we can better understand the generalizations and cross validate the effects of alcohol use on later educational attainment.

\section{Research questions and hypotheses}

\section{Research question 1:}

Will heavy episodic drinking (i.e., number of times binged in the past year and number of times drunk in the past year) in middle school aged adolescents predict educational attainment in high school, such that those individuals who have more instances of heavy episodic drinking will either drop-out of high school or not continue to college compared to those adolescents who do not drink as much?

Hypothesis 1: Heavy episodic drinking in middle school aged adolescents will predict a lower educational attainment. Those with higher rates of heavy episodic drinking will be less likely to finish high school or continue to college compared to those who either abstain or drink at lower levels.

\section{Research question 2:}

Will heavy episodic drinking in middle school aged adolescents result in problems in the adolescents' immediate contexts (i.e., problems with parents due to 
alcohol, problems with peers due to alcohol, and problems with romantic partners due to alcohol)?

Hypothesis 2: Heavy episodic drinking in middle school aged adolescents will be significantly related to problems with adolescents' immediate context (i.e., problems with parents due to alcohol, problems at school due to alcohol, and problems with romantic partners due to alcohol); however, heavy episodic drinking will not be significantly related to problems with peers due to alcohol.

\section{Research question 3:}

Will problems in the middle school aged adolescents' immediate contexts (i.e., problems with parents due to alcohol, problems at school due to alcohol, and problems with romantic partners due to alcohol, problems with peers due to alcohol) mediate the relationship between heavy episodic drinking and educational attainment?

Hypothesis 3: Problems in the middle school aged adolescents' immediate contexts (i.e., problems with parents due to alcohol, problems at school due to alcohol, and problems with romantic partners due to alcohol) will mediate the relationship between heavy episodic drinking and educational attainment. It is expected, however, that the relationship between heavy episodic drinking and educational attainment will not be mediated with problems with peers due to alcohol.

\section{Research question 4:}

Will heavy episodic drinking in older adolescents (i.e., seniors in high school), predict educational attainment in college, (i.e., Time 3), such that those individuals who have more heavy episodic drinking tendencies will drop out of college? 
Hypothesis 4: Heavy episodic drinking in older adolescents will predict a lower educational attainment, such that those with higher rates of heavy episodic drinking will be less likely to finish college when compared to those who either abstain or drink at lower levels.

\section{Research question 5:}

Will heavy episodic drinking at Time 1 for $12^{\text {th }}$ graders predict problems in the adolescents' immediate contexts ( i.e., problems with parents due to alcohol, problems with school due to alcohol, problems with peers due to alcohol, and problems with romantic partners due to alcohol)?

Hypothesis 5: Heavy episodic drinking in older adolescents will be significantly related to problems with adolescents' immediate context (i.e., problems with parents, problems at school, and problems with romantic partners); however, heavy episodic drinking will not be significantly related to problems with peers.

\section{Research question 6:}

Will problems in the older adolescents' immediate contexts (i.e., problems with parents due to alcohol, problems at school due to alcohol, and problems with romantic partners due to alcohol, problems with peers due to alcohol), mediate the relationship between heavy episodic drinking and educational attainment?

Hypothesis 6: Problems in the older adolescents' immediate contexts, i.e., problems with parents due to alcohol, problems at school due to alcohol, and problems with romantic partners due to alcohol, will mediate the relationship between heavy episodic drinking and educational attainment. It is expected however, that the relationship 
between heavy episodic drinking and educational attainment will not be mediated with problems with peers due to alcohol.

Given the mixed findings concerning heavy episodic drinking in relation to gender (Center for Disease Control and Prevention, 2006; Ham \& Hope, 2003, Johnston et al., 2008), no formal hypotheses were made regarding the possible gender differences in the models. 


\section{METHODOLOGY}

\section{Participants}

The study used data from the National Longitudinal Study of Adolescent Health (Add Health; Bearman, Jones, \& Udry 1997). This was a large scale, nationally representative school based sample of 20,745 adolescents who were interviewed in grades 7 to 12 . The sampling frame was based on a random sample of 80 high schools stratified by region, urbanism, (urban/suburban/rural); school type, (public/private/parochial); ethnic mix; and size. For each high school, a set of "feeder" schools, which included 7 th and $8^{\text {th }}$ graders, was identified. Some high schools included grades 7 to 12 and functioned as their own feeder school. A total of 134 discrete schools were studied.

Approximately 200 adolescents were selected from each of the schools, including several strategic over-samples (e.g., Blacks with parents who had a college degree). Sampling weights were derived by Add Health statisticians to permit inferences for a nationally representative sample. A parent, in most cases the resident mother, was asked to complete a questionnaire covering topics that overlapped with the adolescent questionnaire as well as information about the economic status of the household.

\section{Procedure}

In-home interviews were conducted with students. Data were recorded on laptop computers. The interviewer read the questions and entered the respondent's answers. For more sensitive sections, the respondent listened to prerecorded questions through earphones and entered the answers directly (audio-CASI). Respondents were reassured 
of the confidentiality of their responses and could skip any questions that they felt uncomfortable about answering. Adolescents and parents were interviewed separately.

The interview included a wide range of topics including: health status, health facility utilization, nutrition, peer networks, decision-making processes, family composition and dynamics, educational aspirations and expectations, to name a few.

Adolescents were interviewed a third time (Wave 3) approximately 5 to 6 years after the first interview. No significant attrition biases were observed across waves on a range of demographic variables, with sampling weights adjusting for attrition and missing data across waves. For methodological details, see the Add Health website at www.cpc.unc.edu/addhealth.

\section{Measures}

Demographics. At all waves, gender, ethnicity, parental educational attainment, home structure were assessed by self-report.

Academic Variables. At all waves, academic aspirations by the adolescents and academic aspirations for the adolescents by their parents, adolescents ratings of school connectedness, GPA, and grade level were assessed by self-report.

Heavy episodic drinking. Participants in Wave 1 were asked "over the past 12 months, on how many days did you drink five or more drinks in a row" and "over the past 12 months, on how many days have you gotten drunk or very, very high on alcohol". These two questions served as indicators for a latent variable of heavy episodic drinking.

Problems in immediate context due to drinking. Respondents in Wave 1 were asked "over the past 12 months, how many of these things happened to you; you got into trouble with your parents because you had been drinking; you had problems with school 
or school work because you had been drinking; you had problems with your friends because you were drinking; you had problems with someone you were dating due to drinking." These responses served as single indicators of problems due to drinking.

Educational Attainment. At Wave 3, educational attainment was evaluated. Self- reports indicate if the student finished high school, highest grade the student completed, and college degree status.

\section{Analytic Strategy}

Add Health used a stratified cluster sampling design in which schools were sampled from the Quality of Education Database. Student-level sampling weights were calculated by Add Health statisticians (Tourangeau \& Shin, 1998). These weights were used to derive parameter estimates and standard errors in the statistical models. The community from which the school was sampled served as the primary sampling unit (PSU). Strata were defined in accord with the clustered sample design. Analyses used the M Plus software for structural equation modeling (SEM), which allows for sampling weights. The model tested is presented in Figure 1. Because the educational attainment outcomes were dichotomous, a limited information estimation strategy with robust estimators was used. 


\section{RESULTS}

\section{Data Analytic Plan}

Two longitudinal mediational models were evaluated utilizing structural equation modeling, (using the MPLUS software; Muthén \& Muthén, 2004; please see Figure 1). Wave 3 data was collected six years after Wave 1 data. These two models are identical, except in the ages of the respondents (i.e., one model examines young adolescents, grades 7-8 and the other model examines older adolescents who are seniors in high school,) and educational attainment at Wave 3 (i.e., high school educational attainment in the $7^{\text {th }} / 8^{\text {th }}$ grade cohort and 4 year college status in the $12^{\text {th }}$ graders).

Missing data were accommodated using Full Information Maximum Likelihood (Honaker, Joseph, King, Scheve, \& Singh, 2003). To determine if the structural coefficients varied as a function of gender, product terms between gender and all Wave 1 hypothesized paths were formed and included in the equations to test for statistical interactions (Jaccard \& Turrisi, 2003). Additionally, ethnicity was treated the same way to explore if these Wave 1 paths differed by ethnicity. The model in Figure 1 was evaluated for the total sample and then again for subgroups defined by gender and by ethnicity. Covariates were included for all endogenous variables; including adolescents' college aspirations, parental income, and parental education. For the analyses on the total sample, gender and ethnicity also were included as covariates. For the gender models, ethnicity was also included as a covariate; for the ethnicity models, gender was also included as a covariate.

Statements are made below about mediation. The current study used the logic of the joint significance test as a basis for stating mediation (MacKinnon, Lockwood, 
Hoffman, West \& Sheets, 2002). This is a superior test of mediation relative to the traditional approach of Baron and Kenny (1986). The logic is that if all path coefficients in a mediated chain are statistically significant, then mediation is declared. The same logic is applied to declarations of statistical significance of total effects.

\section{Global Fit Indices}

Following the recommendations of Bollen and Long (1993), a variety of global fit indices were used. These include the Root Mean Square Error of Approximation (RMSEA; which should be less than 0.08 to declare satisfactory fit), the Comparative Fit Index (CFI; which should be greater than 0.95); and the standardized root mean square residual (which should be less than 0.05).

The $7^{\text {th }} / 8^{\text {th }}$ grade model was examined for goodness of fit. The model was found to be good fitting. The RMSEA was 0.02 , the CFI was 0.99 , and the SRMR was 0.03 , all indicating a good fitting model. The $12^{\text {th }}$ grade model was also evaluated for goodness of fit. The model was found to be good fitting. The RMSEA was 0.04, the CFI was 0.97, and the SRMR was 0.02, all indicating a good fitting model.

\section{Preliminary Analyses}

Descriptive Statistics. Tables 1 and 2 present descriptive statistics for the variables included in both models. Tables 3 and 4 provide the unweighted means and standard deviations, as well as the weighted means and standard errors for the variables included in the study. For a summary of drinking variables for both models, please see Tables 7 and 8 . 


\section{Primary Analyses}

$7^{\text {th }}$ and $8^{\text {th }}$ grade model mediation and outcomes. The behaviors demarcated in Figure 1 as being measured at Wave 1 are contemporaneous with the assessment of heavy episodic drinking behaviors and problems due to alcohol use while educational attainment or high school graduation was measured prospectively six years later (Wave 3). Interaction analyses revealed that there were no moderating effects of gender or ethnicity on proposed paths. The model was then trimmed of the interaction contrasts. Gender and ethnicity were added as covariates for the final full model. Figure 2 presents the significant findings of the study for $7^{\text {th }}$ and $8^{\text {th }}$ graders. Table 5 presents the path coefficients for all paths included in the model - significant and non-significant.

The current study examined two measures of heavy episodic drinking ( i.e., number of days drunk in the past year, number of binge drinking experiences in the past year). However, since they were highly correlated, $\left(\mathrm{r}=.29, p<0.01\right.$ for $7^{\text {th }} / 8^{\text {th }}$ graders and $\mathrm{r}=.83, p<0.01$ for $12^{\text {th }}$ graders), they were combined as two indicators of one latent variable of heavy episodic drinking (LHED). LHED significantly predicted educational attainment, such that for one unit increase of heavy episodic drinking, educational attainment decreased -.03 , (path $e ; p=.04$ ). This indicates that for every one unit increase in heavy episodic drinking the likelihood of graduating decreased by .03 units. This model also examined problems associated with drinking alcohol (i.e., problems with parents due to alcohol, problems with peers due to alcohol, problems with a romantic partner due to alcohol, problems with school due to alcohol) as partial mediators between drinking and educational attainment. There were significant findings associated with these alcohol related problems as well. Specifically, LHED was associated with alcohol 
related problems with (a) parents (path $d$; unstandardized path coefficient $=.25, p<.01$ ), (b) school (path $b$; unstandardized path coefficient $=.13, p<.01$ ), (c) romantic partner (path $a$; unstandardized path coefficient $=.13, p=.00$ ), and (d) peers (path $b$; unstandardized path coefficient $=.11, p<.001)$. In sum, as heavy episodic drinking increased, problems in all four domains also increased proportionally.

It was also hypothesized that alcohol related problems as measured in Wave 1 would predict educational attainment 6 years later in Wave 3. Problems with parents due to alcohol use was the only path that significantly predicted educational attainment (unstandardized path coefficient $=-.05, p<.01$ ), such that for every one unit of increase of problems with parents the likelihood of not graduating from high school decreased by .05 units. Furthermore, since heavy episodic drinking was significantly related to problems with parents due to alcohol use (path $d$ ) and problems with parents due to alcohol use significantly predicted educational attainment (path $i$ ), partial mediation can be declared. Additionally, the path from alcohol related problems with school predicting educational attainment was trending towards significance (path $g$; unstandaridized path coefficient $=-.09, p=.058)$.

\section{$12^{\text {th }}$ grade model mediation and outcomes}

Similar to the previous model with $7^{\text {th }}$ and $8^{\text {th }}$ graders, the behaviors demarcated in Figure 2 as being measured at Wave 1 are contemporaneous with the assessment of heavy episodic drinking behaviors, as well as alcohol related problems. Educational attainment (i.e., attending a four year college or graduate school) was measured prospectively six years later in Wave 3. Interaction analyses revealed that there were no moderating effects of gender or ethnicity on proposed paths. The model was then 
trimmed of the interaction contrasts. Gender and ethnicity were added as covariates for the final full model. Table 7 presents the path coefficient estimates for seventh and eighth graders. Figure 4 presents the significant findings of the study for $12^{\text {th }}$ graders.

For $12^{\text {th }}$ graders, heavy episodic drinking (LHED) in Wave 1 did not significantly predict educational attainment six years later (path $e$ ). However, LHED was significantly associated with alcohol related problems with (a) romantic partner, (path $a$; unstandardized estimate $=.21, p$-value $=.00$ ); (b) school, (path $b$; unstandaridized coefficient $=.06, p$-value $=.02)$; (c) peers, $($ path $c$; unstandardized coefficient $=.05, p$ value $<.05$ ); and (d) parents, (path $d$, unstandaridized coefficient $=.25, p$-value $<.00$ ). As with the previous model, educational attainment (i.e., attending a four year university or graduate school in Wave 3) was predicted by Wave 1 variables. Educational attainment in Wave 3 was not predicted by any of Wave 1 variables. Specifically, for $12^{\text {th }}$ grade students, heavy episodic drinking in Wave 1 did not predict educational attainment in Wave 3. Additionally, college students' contextual alcohol problems (i.e., problems with peers, romantic partner, school, and parents due to alcohol use) in Wave 1 were not predictive of educational attainment in Wave 3.

Additional Analyses. To further explore the relationship between heavy episodic drinking and educational attainment in the $12^{\text {th }}$ grade students, a new educational attainment variable was created in order to examine actual obtainment of a bachelor's degree, (i.e., received a bachelor's degree or did not receive a bachelor's degree). In order to avoid model misspecification, gender and ethnicity were examined as moderator variables. Product terms were introduced into the model for possible interaction effects. In order to examine the gender interaction for the latent heavy episodic drinking variable, 
a latent variable product term was created with two indicators: frequency of days drunk by gender and frequency of binge drinking by gender. This latent variable was included as a predictor for all endogenous variables. No statistically significant gender interactions were found. Similarly, for ethnicity, latent variable product terms were created with two indicators for each ethnic group: frequency of drinking by ethnic group and frequency of binge drinking by ethnic group. The White group was initially excluded as the reference group for each latent variable. To examine all possible contrasts across ethnic groups, the reference group was rotated for each moderated path examined. The Holm modified Bonferroni technique was used to account for elevated experiment error rate due to multiple contrasts.

As with gender, no statistically significant interactions by ethnic group were found. As a result of the above, both gender and ethnicity were included as covariates for all subsequent model runs. Similarly to the previous model, it was found that heavy episodic drinking did not predict educational attainment in college. Thus, those individuals who drank heavily in $12^{\text {th }}$ grade still obtained a bachelor's degree. 


\section{DISCUSSION}

The purpose of this dissertation study was to examine two models of heavy episodic drinking and subsequent educational attainment. The study's results extend previous research by providing a better understanding of the generalizability of the effects of alcohol use on later educational attainment through the use of two different transitional time points: middle school to high school; and high school to college completion.

\section{Middle school alcohol use and the completion of high school.}

One of the primary aims of this study was to shed light on the impact that early heavy episodic drinking may have on high school educational attainment. High school educational attainment is an important milestone for development and later positive life outcomes. Therefore, it is important to understand risk factors (e.g., heavy episodic alcohol use, problems in a variety of contexts due to alcohol use) that may impede completion of high school. Consistent with Hypothesis 1, heavy episodic drinking in middle school was found to be inversely related to educational attainment six years later (path $e$ ). Additionally, there were no gender or ethnic effects on this relationship. Because heavy episodic drinking does occur in this age group, the current study has important implications for alcohol prevention and intervention programs in American middle schools and high school. If adolescents engage in heavy early drinking, they may not obtain a high school degree. By not obtaining a high school degree, these individuals are at risk for living in poverty, being unemployed and perpetuating the cycle by having children who drop out themselves (Bridgeland, 2006). 


\section{Direct effects of LHED on problems with context due to alcohol use.}

Regarding the contextual problems associated with alcohol (i.e., Hypothesis 2); there were several significant relationships for $7^{\text {th }}$ and $8^{\text {th }}$ graders. When examining past year heavy episodic drinking, it was found that heavy episodic drinking predicted problems in the school setting and in relationships with parents, peers, and romantic partners (paths $a$ $-d$ ). Many prominent theories and much of the alcohol literature premise that students drink with and partially due to their peers (e.g., Barnes, Hoffman, Welte, Farrell \& Dintcheff, 2006; Petraitis, Flay, \& Miller, 1995). However, LHED still predicted problems with peers. It may be that drinking with peers is acceptable, but it may not be acceptable to become severely intoxicated. As drinking is linked to many aggressive outcomes (e.g., Rossow, 1996; Rossow, Pape, \& Wichstrom, 1999) a relationship may exist where the more times an individual becomes drunk, the more chances he or she has to act in a manner that may anger his or her friends by getting into an argument or getting into a physical altercation. As the individual continues to binge drink and have episodes of being drunk, these chances for aggression increase thus leading to problems with friends due to alcohol use.

In line with the current study's hypotheses, LHED predicted problems with romantic partner and problems with school due to alcohol use (i.e., Hypothesis 2; paths $a$ and $b$ ) . However, the current study did not examine pre-existing relationship problems, which could have compounded the alcohol related problems. Heavy alcohol use in adolescence has been linked to dating violence (Reyes, Foshee, Bauer, \& Ennet, 2011).

\section{Indirect effects of LHED on problems with context due to alcohol use.}

Contrary to the study hypothesis (i.e., Hypothesis 3), there was only one mediated 
relationship; the relationship between educational attainment and LHED was mediated by problems with parents due to alcohol (path $d$ ). It may be the more often a student gets drunk, the more likely the parent will find out about their child's alcohol consumption. Then, the parent(s) and student may have interpersonal problems due to the student drinking at high levels and at such a young age in adolescence. In a similar vein, van der Vorst, Engels, Meeus, and Dekovic (2006) conducted a longitudinal study examining parental attachment and early drinking. Van der Vorst et al. found that the more an adolescent consumed alcohol, the less strong the adolescent felt his or her attachment relationship was with his or her parent. Thus, the relationship between parent and child may be affected because of alcohol. If there is conflict in the home due to the alcohol use (i.e., problems with parents due to alcohol use), the adolescent may then continue to use alcohol as a coping mechanism. Therefore, the home environment becomes more unstable, and the adolescent moves further away from the goal of a high school diploma. Additionally, as the frequency of alcohol usage increases, other risk behaviors may occur, which also preclude an educational attainment (i.e., other substance use, risky sexual behavior, teenage pregnancy, truancy) and may affect the parent-child relationship. Problems with parents mediating the relationship between LHED and educational attainment is important in terms of prevention and intervention efforts.

The current study adds to the literature in that it highlights the need for parental engagement in regards to adolescents' alcohol use (Guilamo-Ramos et al., 2005). For instance, Guilamo-Ramos et al. found a curvilinear relationship between binge drinking and parental control/supervision such that moderate levels of control/supervision are 
optimal, whereas when control/supervision is at the bare minimum, binge rates increased. When control/supervision increased past a specific level, binge rates also increased.

One possible explanation of the Guilamo-Ramos and colleagues (2005) finding is that some parents may not control their children at all, regardless of the adolescent's alcohol use. Other parents, when faced with adolescent drinking, may move to an overcontrol position. This over-control position may also be harmful to the adolescent and increase the adolescent's drinking. For instance, Engels and van der Vorst (2003) found that harsh discipline affected drinking behavior greatly, (i.e., the harsher the discipline, the more likely drinking behavior increased).

In contrast to the over-controlling or overly permissive parent, Guilamo-Ramos et al. (2005) found that higher levels of communication satisfaction with one's parents, using reasoning, and explanation by the parent also deterred binge drinking rates. These studies highlight the importance of parents in adolescent drinking. Parental engagement with their child's alcohol intervention may help increase the educational attainment of these youngsters. In fact, several studies have found preventive interventions aimed at alcohol use with adolescents are more effective when parents are included simultaneously (e.g., Smit, Verdurmen, Monshouwer, \& Smit, 2008; Wu, Stanton, Galbraith, Kaljee, Cottrell, Li, Harris, D’Alessandri, \& Burns, 2003).

Although the current study found a significant positive relationship between LHED and problems with school due to alcohol, it was interesting to note that the problems in school due to alcohol were not predictive of educational attainment, (i.e., Hypothesis 3$)$ even though this relationship was approaching significance $(p=.058)$. Most schools tend to expel their students as a punishment for problem drinking, instead 
of working with them toward change; many researchers have cautioned the expulsion of students with drinking infractions (i.e., Guilamo-Ramos, Jaccard, Turrisi, \&, Johansson, 2005). This study demonstrated that not only the direct effects of heavy episodic drinking affect educational attainment, but additionally the indirect effects also affect educational attainment (i.e., the mediated relationship). This may change the way intervention and prevention efforts for academic achievement are implemented in middle school.

\section{$12^{\text {th }}$ grade students and college educational attainment}

Contrary to the current study's hypothesis, LHED did not predict educational attainment (Hypothesis 4; path $e$ ). This finding is noteworthy given the vast literature surrounding college drinking (e.g. King, Meehan, Trim, \& Chassin, 2006). A possible explanation for this finding is that the students continue in college and begin to adopt adult roles, with many students "maturing out" of binge or risky drinking. As with the previous model, it could also be that the students compartmentalize their drinking to only certain contexts and time (e.g., at bars and on the weekends). Additionally, in light of Wood et al.'s (2004) findings, it could be there are several other variables, such as family history of clinical diagnoses and prior academic failure, that may account for negative educational attainment outcomes other than alcohol use .

\section{Direct effects of of LHED on problems with context due to alcohol use.}

Contrary with the study's hypothesis, LHED was related to problems with peers (Hypothesis 5). This was an unexpected finding as many of college's activities have a drinking component, making college a time and place where drinking is socially acceptable. Furthermore, research on alcohol use during college has focused on 
examining peer norms, peer alcohol usage, and peer influence on alcohol usagee; however, there is a paucity of research examining problems with friends due to alcohol use. Again, one could hypothesize that peers have a certain threshold of acceptability of drinking. Perhaps when the individual begins to drink in excess, he or she is overestimating others' alcohol use, thus not seeing it as a problem. In line with that idea, studies have demonstrated the heavy episodic drinkers overestimate the leniency of other student's attitudes towards drinking (Perkins \& Berkowitz, 1986). Additionally, students are typically biased in terms of perceived norms for drinking frequency and quantity (Baer, 2002). It could be this overestimation and bias that leads to having problems with friends due to alcohol use Additionally Wechsler, Davenport, Dowdall, Moeykens, and Castillo (1994) found binge drinkers were 25 more times likely, when compared to nonbinge drinkers, to endorse many negative consequences when drinking, including fighting with friends.

Also consistent with the study's hypotheses, LHED predicted problems with romantic partner and problems with school due to alcohol use (Hypothesis 5; path $a$ and b). As many studies have pointed to alcohol impacting romantic relationships (e.g., Leonard \& Roberts, 1998), it is unsurprising that LHED predicted problems in a romantic relationship due to alcohol It is also not surprising that heavy episodic drinking would lead to having problems with school due to alcohol. Studies have shown that frequent binge drinkers were more likely to miss class, have a hangover, and fall behind in school when compared to nonbinge drinkers (Wechsler et al., 1994)

It was also found that LHED predicted problems with parents due to alcohol use (path $d$ ). Most of the research examining heavy episodic drinking and parents typically 
examines how parental attitudes, permissiveness towards alcohol, and parental nurturance affect college students' drinking behaviors (Reifman, Barnes, Dintcheff, Farrell, \& Uhteg, 1998; Wood, Read, Mitchell, \& Brand,). The current study demonstrates that heavy episodic drinking may lead to problems with parents due to alcohol. It would be interesting to see how parental attitudes and permissiveness towards drinking may or may not change after the student has problems with their parents due to alcohol use.

$12^{\text {th }}$ grade indirect effects. Interestingly, even though LHED predicted problems with school due to drinking, problems with school did not predict educational attainment (Hypothesis 6). A possible explanation for this finding is that alcohol prevention and intervention efforts on college campuses may have affected these analyses. Although LHED did not predict educational attainment using either outcome variable for educational attainment (i.e., in a four year program or in a graduate program; actual obtainment of a bachelor's degree), it is still important to note that LHED did predict problems in a variety of contexts due to alcohol use (i.e., dating, school, peers, and parents) . For instance, abusive consumption has been estimated to be responsible for 70,000 incidences of sexual abuse/rapes, 600,000 incidents of assault, 72 deaths per weekend, 500,000 injuries, 1 in 4 individuals reporting academic problems (Hingson, Heeran, Zakocs, Kopstein, \& Wechsler, 2002). It is important not to overlook the problems that heavy alcohol use is related to, despite not being related to educational attainment in this study. 


\section{Limitations and Directions for Future Research}

Although the results of the current study provide important implications for future research, several limitations can be noted. First, the outcome of Wood et al.'s (2004) study suggest there may be other factors that affect the relationship between heavy episodic drinking and educational attainment. The current study did not examine specific environmental or individual factors that may either strengthen or weaken the relationship between alcohol usage and educational attainment. Secondly, this study did not control for other risk behavior that could have resulted or was concurrent with alcohol use and which may have also been determinants to educational attainment in $7^{\text {th }}$ and $8^{\text {th }}$ grade. For example, previous research has correlated teen alcohol usage with unplanned pregnancy, risky sexual encounters, legal problems, mental health problems, and other drug usage (e.g., Centers for Disease Control and Prevention; Kirby, 2002), all of which can influence academic functioning.

Furthermore, the current study did not take into account the quality of the parentchild relationship prior to the alcohol problems. By not controlling for parent-child relationship, it is unclear if the problems with parents may have preceded the heavy episodic drinking. In the middle school aged youth, it is important to understand the type and intensity levels of the problems adolescents had with their parents. It is impossible to tell from these analyses if the problems with parents increased alcohol use, which in turn increased the likelihood of the students' not obtaining a high school degree. Positive parental nurturance, parental monitoring, and parent-adolescent communication have been found to inversely relate to adolescent alcohol use (Windle et al., 2008). As there were only three waves available at the time of the current study, future research should 
examine these relations with Wave 4 data to examine possible bi-directional effects of alcohol on problems with parents.

Additionally, this study did not measure if the adolescents or college students had received treatment for alcohol use between time points. Specifically, for college students, more campuses are engaging in prevention and intervention work with those students who are facing disciplinary action due to drinking. It could be that those individuals who were in danger of dropping out of school received an intervention which lessened the likelihood that they were expulsed or dropped out of school.

The current study also only assessed whether the $12^{\text {th }}$ graders attended a four year university or graduate school or obtained a bachelor's degree, omitting individuals who obtained an associates degree or a technical degree. Omitting these individuals eliminates the possibility of comparing different life paths that individuals may take once leaving high school.

Taking these limitations into account, this study is still one of importance as the generalizability of alcohol's effects on educational attainment was examined across two independent samples, allowing for cross validation of these effects._Identifying patterns in alcohol use across adolescence and young adulthood is important. Many developmental tasks, both within the organism and outside the organism, occur during these time periods which have implications on individual development (Masten et al., 2008). While there have been other studies examining heavy episodic drinking and educational attainment (e.g., Schulenberg, Bachman, O’Malley \& Johnston, 1994), longitudinal research is still needed to examine the transition points and possible points for intervention. Prospective longitudinal studies are needed as cross-sectional studies 
may miss important transition points and retrospective studies require confirmation that is often unavailable (Masten et al., 2008). Alcohol involvement in adolescence has both long-term and short-term consequences on later mental health and well-being. Given that research indicates that adolescents are particularly vulnerable to adverse effects in biological and social functioning, problem drinking has the potential to alter an individual's life course towards a risky path (Brown et al., 2008).

The current study adds to this literature by increasing the awareness that the direct effects of heavy episodic drinking may not affect educational attainment in college students. Future research should examine what factors continue to sustain the student in college despite his or her risky drinking. These factors might be utilized to help researchers, policy makers, and universities target the protective factors that preclude college drop-out.

By utilizing two different developmental transitions (i.e., middle school to high school; high school to college), it may be possible to better understand the temporal effects of alcohol use and subsequent educational attainment. Future research should build upon this study by including additional components to trace alcohol use across time to see if the continued use of alcohol affects educational attainment. Research has shown that over time the percentage of students who increase in binge drinking increases over time (e.g., Shope, Copeland, \& Dielman, 1994), such that measurement in $7^{\text {th }}$ and $8^{\text {th }}$ grade may lead to misspecification by underestimating drinking rates as time continues. 


\section{REFERENCES}

Baer, J. S. (2002). Student factors: Understanding individual variation in college drinking. Journal of Studies on Alcohol, S14, 40-53.

Barnes, G. M., Hoffman, J. H., Welte, J. W., Farrell, M. P., \& Dintcheff, B. A. (2006). Effects of parental monitoring and peer deviance on substance use and delinquency. Journal of Marriage and the Family, 68, 1084-1104.

Bearman, P. S., Jones, J., \& Udry, J. R. (1997). The National Longitudinal Study of Adolescent Health: Research design. Available at http://www.cpc.unc.edu/addhlth.

Bridgeland, J. M., Dilulio, J. J., Morison, K. B. (2006). The silent epidemic: Perspectives of high school drop-outs. Retrieved from: http://www.civicenterprises.net/pdfs/thesilentepidemic3-06.pdf

Centers for Disease Control and Prevention Surveillance Summaries. 2006. Morbidity and Mortality Weekly Report, 55.

Delucchi, K. L., Matzger, H., \& Weisner, C. (2008). Factors affecting 7-year alcohol consumption in young adults: Volume and binge frequency. Addictive Behaviors, $33,134-142$.

Engels, R. C. M. E., \& van der Vorst, H. (2003). The roles of parents in adolescent and peer alcohol consumption. The Netherlands' Journal of Social Sciences, 39, $53-$ 68 .

Guilamo-Ramos, V., Jaccard, J., Turrisi, R., \& Johansson, M. (2005). Parental and school correlates of binge drinking among middle school students. American Journal of Public Health, 95, 894-899.

Hair, E. C., Park, M. J., Ling, T. J., \& Moore, K. A., (2009). Risky behaviors in late adolescence: Co-occurance, predictors, and consequences. Journal of Adolescent Health, 45, 253-261.

Ham, L .S. \& Hope, D. A. (2005). Incorporating social anxiety into a model of college student problematic drinking. Addictive Behaviors, 30, 127-150.

Hawkins, J. D., Catalano, R. F., \& Miller, J. Y. (1992). Risk and protective factors for alcohol and other drug problems in adolescence and early adulthood: Implications for substance abuse prevention. Psychological Bulletin, 112, 64-105. 
Hingson RW, Heeren T, Zakocs RC, Kopstein A, Wechsler H (2002). Magnitude of alcohol-related mortality and morbidity among U.S. college students ages 18-24. Journal of Studies on Alcohol and Drugs, 63, 136-144.

Johnson, L. D.,O’Malley, P. M., Bachman, J. G., \& Schulenberg, J. E. (2008). Monitoring the future national results on adolescent drug use: Overview of key findings, 2003. Bethesda, MD: National Institute of Drug Abuse.

King, K. M., Meehan, B.T., Trim, R. S., \& Chassin, L. Research report: Marker or mediator? The effects of adolescent substance use on young adult educational attainment. Addiction, 101, 1730-1740.

Kirby, D. (2002). Antecedents of adolescent initiation of sex, contraceptive use, and pregnancy. American Journal of Health Behavior, 26, 473-485.

Labouvie, E. W. \& White, H. R.(1998). Drug Sequences, age of onset, and use trajectories: Antecedents and adult use outcomes. Paper presented at Conference on Stages and Pathways of Drug Involvement: Examining the gateway hypothesis. Los Angeles, CA, June 1998.

Lanza, S. T. \& Collins, L. M. (2006). A mixture model of discontinuous development in heavy drinking from ages 18 to 30: The role of college enrollment. Journal of Studies on Alcohol, 67, 552-561.

Leonard, K. E., \& Roberts, L. J. (1998). The effects of alcohol on the marital interactions of aggressive and nonaggressive husbands and their wives. Journal of Abnormal Psychology, 107, 602-615.

Kandel, D. B. (1978). Converges in prospective longitudinal surveys of drug use in normal populations. In Kandel, D. B. (Eds.), Longitudinal Research on Drug use (3-38). Washington, DC: Hemisphere.

Kessler, R. C., Foster, C. L., Saunders, W. B., Stang, P. E. (1995). Social consequences of psychiatric disorders, I: Educational Attainment. American Journal of Psychiatry, 152, 1026-1032.

MacDonald, G., Zanna, M. P., \& Holmes, J. G. (2000). An experimental test of the role of alcohol in relationship conflict. Journal of Experimental Social Psychology, 36, 182-193.

Martinez, J. A., Sher, K. J., \& Wood, P. K. (2008). Is heavy drinking really associated with attrition from college? The alcohol-attrition paradox. Psychology of Addictive Behaviors, 22, 450-456. 
Muthén, L. K. \& Muthén, B. O. (2006) Mplus User’s Guide. Los Angeles: Muthen \& Muthen.

National Center for Health Statistics. Health, United States 2007 with Chartbook on Trends in the Health of Americans. Hyattsville, MD: Centers for Disease Control and Prevention, National Center for Health Statistics, 2007. Available at http://www.cdc.gov/nchs/data/hus/hus07.pdf(PDF). Accessed February 28, 2010.

Newcomb, M. D. \& bentler, P. M. (1986). Drug use, educational aspirations, and work force involvement. The transition from adolescence to young adulthood. American Journal of Community Psychology, 14, 302-321.

O'Malley, P.M., \& Johnston, L.D. (2002) Epidemiology of alcohol and other drug use among American college students. Journal of Studies on Alcohol, Suppl. 14, 2339.

Perkins, H. W., \& Berkowitz, A. D. (1986). Perceiving the community norms on alcohol use among students: Some research implications for campus alcohol education programming. International Journal of Addiction, 21, 961-976.

Petraitis, J., Flay, B. R., \& Miller, T. Q. (1995). Reviewing theories of adolescent substance use: Organizing pieces in the puzzle. Psychological Bulletin, 117, $67-86$.

Reyes, H. L. M., Foshee, V. A., Bauer, D., \& Ennet, S. T. (2011). The role of heavy alcohol use in the developmental process of desistence in dating aggression during adolescence. Journal of Abnormal Child Psychopathology, 39, 239-250.

Reifman, A., Barnes, G. M., Dintcheff, B. A., Farrell, M. P., \& Uhteg, L.(1998). Parental and peer influences on the onset of heavier drinking among adolescents. Journal of Studies on Alcohol, 59, 311-317.

Rossow I. (1996). Alcohol-related violence: the impact of drinking pattern and drinking context. Addiction, 91, 1651-61.

Rossow I, Pape H, \& Wichstrom L. (1999). Young, wet and wild? Associations between alcohol intoxication and violent behaviour in adolescence. Addiction,94, 1017-31.

Shope, J. T., Copeland, L. A., \& Dielman, T. E. (1994). Measurement of alcohol use and misuse in a cohort of students followed from grade 6 through grade 12. Alcoholism: Clinical and Experiemtnal Research, 18, 726-733. 
Schulenberg, J., Bachman, J. G., O’Malley, P. M., \& Johnston, L. D. (1994). High school educational success and subsequent substance use: A panel analysis following adolescents into young adulthood. Journal of Health and Social Behavior, 35, 4562.

Slutske, W. S., Hunt-Carter, E. E., Nabors-Oberg, R. E., Sher, K. J., Bucholz, K. K., Madden, P. A., Anokhin, A., et al., (2004). Do college students drink more than their non-college-attending peers? Evidence from a population-based longitudinal female twin study. Journal of Abnormal Psychology, 113, 530-540.

Slutske, W. S. (2005). Alcohol use disorders among US college students and their noncollege attending peers. Archives of General Psychiatry, 62, 321-327.

Smit E., Verdurmen J., Monshouwer K., \& Smit F. (2008) Family interventions and their effect on adolescent alcohol use in general populations; a meta-analysis of randomized controlled trials. Drug and Alcohol Dependence, 97, 195-206.

Substance Abuse and Mental Health Services Administration (2007). The NSDUH Report: Gender differences in alcohol use and alcohol dependence or Abuse2004 and 2005. Retrieved from http://www.oas.samhsa.gov/2k7/AlcGender/AlcGender.pdf.

Tucker, J. S., Ellickson, P. L., Orlando, M., Martino, S. C., \& Klein, D. J. (2005). Substance use trajectories from early adolescence to emerging adulthood; A comparison of smoking, binge drinking, and marijuana use. Journal of Drug Issues, 35, 307-332.

Wechsler, H., Davenport, A., Dowdall, G., Moeykens, B., \& Castillo, S. (1994). Health and behavioral consequences of binge drinking in college. Journal of the American Medical Association, 272, 1672-1677.

Windle, M., \& Windle, R. C. (2005). Alcohol consumption and its consequences among adolescents and young adults. Recent Advances in Alcoholism, 17, 67-83.

Wood, M. D., Read, J. P., Mitchell, R. E., \& Brand, N. H. (2004). Do parents still matter? Parent and peer influences on alcohol involvement among recent high school graduates. Psychology of Addictive Behaviors, 18, 19-30.

Wood, P. K., Sher, K. J., Erickson, D. J., \& DeBord, K. A. (1997). Predicting academic problems in college from freshman alcohol involvement. Journal of Studies on Alcohol, 200-210. 
Wu Y., Stanton B. F., Galbraith J., Kaljee L., Cottrell L., Li X. Harris, C. V., D’Alessandri, D., \& Burns, J. (2003). Sustaining and broadening intervention impact: a longitudinal randomized trial of 3 adolescent risk reduction approaches. Pediatrics, 111, 32-8.

York, J. L.(1995). Progression of alcohol consumption across the drinking career in alcoholics and social drinkers. Journal on Studies on Alcohol, 56, 328-336.

Zucker, R. A., (1987). The four alcoholisms: A developmental account of the etiologic process. In P. C. Rivers (Ed.), Alcohol and addictive behavior ( pp. 27-83). Lincoln, NE: University of Nebraska Press. 


\section{Table 1.}

Summary of Age, Ethnicity, and Study Variables for the Seventh and Eighth graders $(N=3531)$.

\begin{tabular}{|c|c|c|c|}
\hline Variable & $\begin{array}{l}\text { Unweighted } \\
\text { n (\%) }\end{array}$ & Weighted \% & $S E$ \\
\hline Age at Wave 1 & $13.7(S D=1.8)$ & 13.5 & .02 \\
\hline Median parental income & 26,000 & & \\
\hline \multicolumn{4}{|l|}{ Gender } \\
\hline Female & & 49.7 & $.6 \%$ \\
\hline Male & & 50.3 & $.6 \%$ \\
\hline \multicolumn{4}{|l|}{ Race/Ethnicity } \\
\hline Asian or Asian American & $59(8.7 \%)$ & $3.7 \%$ & $.7 \%$ \\
\hline Black or African American (non- & $130(19.1 \%)$ & $15.3 \%$ & 2.0 \\
\hline Hispanic) & & & \\
\hline Hispanic or Latino(a) & $124(18.3 \%)$ & $11.6 \%$ & $1.7 \%$ \\
\hline Native American or American Indian & $5(0.7 \%)$ & $.9 \%$ & $.3 \%$ \\
\hline
\end{tabular}




\section{Table 1.}

Summary of Age, Ethnicity, and Study Variables for the Seventh and Eighth graders $(N=3531)$.

\begin{tabular}{|c|c|c|c|}
\hline Variable & Unweighted n (\%) & Weighted \% & SE \\
\hline \multicolumn{4}{|l|}{ Parental Education } \\
\hline Never attended school & $4(.1 \%)$ & $.2 \%$ & $.1 \%$ \\
\hline Less than $8^{\text {th }}$ & $148(4.2 \%)$ & $3.6 \%$ & $.7 \%$ \\
\hline Did not graduate High School & $392(11.1 \%)$ & $11.5 \%$ & $1.2 \%$ \\
\hline High School Degree & $1032(29.2 \%)$ & $29.8 \%$ & $1.4 \%$ \\
\hline Trade School & $543(15.4 \%)$ & $15.0 \%$ & $1.1 \%$ \\
\hline College but no degree & $627(17.8 \%)$ & $17.9 \%$ & $.9 \%$ \\
\hline College degree & $485(13.7 \%)$ & $12.9 \%$ & $1,1 \%$ \\
\hline Professional beyond college & $300(8.5 \%)$ & $7.6 \%$ & $.9 \%$ \\
\hline \multicolumn{4}{|l|}{ Educational attainment (Wave 3) } \\
\hline Graduated from High School or GED & $3045(86.3)$ & $85.6 \%$ & $1.3 \%$ \\
\hline Did not Graduate From High School & $482(13.7 \%)$ & $14.4 \%$ & $1.3 \%$ \\
\hline
\end{tabular}




\section{Table 2.}

Summary of Age, Ethnicity, and Study Variables for $12^{\text {th }}$ graders $(N=679)$.

\begin{tabular}{|c|c|c|c|}
\hline Variable & Unweighted n (\%) & Weighted \% & $\mathrm{SE}$ \\
\hline Age at Wave 1 & $17.5(S D=1.3)$ & $15.4 \%$ & .11 \\
\hline Median parent income & 35,000 & & \\
\hline \multicolumn{4}{|l|}{ Gender } \\
\hline Female & $370(54.5 \%)$ & $49.1 \%$ & $2.9 \%$ \\
\hline Male & $309(45.5 \%)$ & $50.9 \%$ & $2.9 \%$ \\
\hline \multicolumn{4}{|l|}{ Race/Ethnicity } \\
\hline Asian or Asian American & $59(8.7 \%)$ & $3.7 \%$ & $.7 \%$ \\
\hline Black or African American (non- & & $15.3 \%$ & 2.0 \\
\hline \multicolumn{4}{|l|}{ Hispanic) } \\
\hline Hispanic or Latino(a) & $124(18.3 \%)$ & $11.6 \%$ & $1.7 \%$ \\
\hline Native American or American Indian & $5(0.7 \%)$ & $.9 \%$ & $.3 \%$ \\
\hline White or Caucasian (not Hispanic) & $349(51.4 \%)$ & $68.4 \%$ & $2.8 \%$ \\
\hline
\end{tabular}


Table 2.

Summary of Age Ethnicity, and Study Varaibles for $12^{\text {th }}$ graders $(\mathrm{N}=679)$.

\begin{tabular}{|c|c|c|c|}
\hline Variable & $\begin{array}{c}\text { Unweighted } \\
\mathrm{n}(\%)\end{array}$ & Weighted & $\mathrm{SE}$ \\
\hline \multicolumn{4}{|l|}{ Parental Education } \\
\hline Never attended school & $0(0 \%)$ & $.1 \%$ & $.1 \%$ \\
\hline Less than $8^{\text {th }}$ & $60(8.8 \%)$ & $4.1 \%$ & $.6 \%$ \\
\hline Did not graduate High School & $89(13.1)$ & $10.0 \%$ & $.8 \%$ \\
\hline High School Degree & $178(26.2 \%)$ & $30.4 \%$ & $1.1 \%$ \\
\hline Trade School & $109(16.1 \%)$ & $15.4 \%$ & $.7 \%$ \\
\hline College but no Degree & $125(18.4 \%)$ & $18.9 \%$ & $.7 \%$ \\
\hline College Degree & $75(11 \%)$ & 13.2 & $.7 \%$ \\
\hline Professional Beyond College & $43(6.3 \%)$ & $7.9 \%$ & $.7 \%$ \\
\hline \multicolumn{4}{|l|}{$12^{\text {th }}$ graders educational attainment at Wave 3} \\
\hline Not in school or in a community college & $590(86.9 \%)$ & $86.9 \%$ & $1.9 \%$ \\
\hline \multicolumn{4}{|l|}{ Attended four year college or graduate } \\
\hline School & $86(12.7 \%)$ & $13.1 \%$ & $1.9 \%$ \\
\hline
\end{tabular}




\begin{tabular}{|c|c|c|c|c|}
\hline \multicolumn{5}{|c|}{$\begin{array}{l}\text { Table } 3 . \\
\text { Summary of Study Variables for Seventh and Eighth graders: Wave } 1(N=3531)\end{array}$} \\
\hline Variable & Unweighted Mean & SD & Weighted Mean & SE \\
\hline $\begin{array}{l}\text { Number of } \\
\text { days drunk in } \\
\text { the past year }\end{array}$ & .29 & .45 & .28 & .02 \\
\hline $\begin{array}{l}\text { Days five } \\
\text { drinks or more } \\
\text { in the past year }\end{array}$ & .31 & .99 & .29 & .03 \\
\hline $\begin{array}{l}\text { Problems with } \\
\text { parents due to } \\
\text { alcohol }\end{array}$ & .27 & .73 & .31 & .03 \\
\hline $\begin{array}{l}\text { Problems with } \\
\text { school due to } \\
\text { alcohol }\end{array}$ & .13 & .57 & .11 & .02 \\
\hline $\begin{array}{l}\text { Problems with } \\
\text { friends due to } \\
\text { alcohol }\end{array}$ & .17 & .56 & .16 & .02 \\
\hline $\begin{array}{l}\text { Problems with } \\
\text { romantic } \\
\text { partner due to } \\
\text { alcohol }\end{array}$ & .18 & .57 & .14 & .02 \\
\hline
\end{tabular}


Table 4.

Summary of Study Variables for Twelfth graders $(N=679)$

\begin{tabular}{|c|c|c|c|c|}
\hline Variable & $\mathrm{M}$ & SD & Weighted Mean & $\mathrm{SE}$ \\
\hline $\begin{array}{l}\text { Number of days } \\
\text { drunk in the past } \\
\text { year }\end{array}$ & .99 & 1.5 & .56 & .03 \\
\hline $\begin{array}{l}\text { Days five drinks } \\
\text { or more in the } \\
\text { past year }\end{array}$ & 1.0 & 1.6 & .57 & .03 \\
\hline $\begin{array}{l}\text { Problems with } \\
\text { parents due to } \\
\text { alcohol }\end{array}$ & .33 & .77 & .33 & .02 \\
\hline $\begin{array}{l}\text { Problems with } \\
\text { school due to } \\
\text { alcohol }\end{array}$ & .22 & .60 & .1 & .01 \\
\hline $\begin{array}{l}\text { Problems with } \\
\text { friends due to } \\
\text { alcohol }\end{array}$ & .22 & .58 & .18 & .01 \\
\hline $\begin{array}{l}\text { Problems with } \\
\text { romantic partner } \\
\text { due to alcohol }\end{array}$ & .38 & .82 & .25 & .01 \\
\hline
\end{tabular}




\section{Table 5.}

Model Path Coefficients for Seventh and Eighth graders

Paths B

B p-value

$95 \% \mathrm{CI}$

Path $a:$ LHED $\rightarrow$ problems with

0.13

0.00

0.77 to 0.17

Romantic partner due to alcohol

Path $b:$ LHED $\rightarrow$ problems with

0.13

0.00

0.77 to 0.17

school due to alcohol

Path $c:$ LHED $\rightarrow$ problems with

0.11

0.00

0.06 to 0.16

peers due to alcohol

Path $d:$ LHED $\rightarrow$ problems with

0.25

0.00

0.17 to 0.33

parents due to alcohol

Path $e:$ LHED $\rightarrow$ educational

0.03

0.04

0.01 to 0.05

attainment

Path $f$ : Problems with romantic

0.04

0.19

0.02 to 0.10

partner due to alcohol $\rightarrow$ educational attainment

Path g: Problems with school due to

alcohol $\rightarrow$ educational attainment

0.9

0.06

-0.004 to

Path $h$ : Problems with peers due to alcohol $\rightarrow$ educational attainment

$\begin{array}{lll}-0.04 & 0.40 & -0.12 \text { to } 0.05\end{array}$

Path $i$ : Problems with parents due to

$-0.05$

0.013

0.10 to 0.09

Note. B signifies unstandardized path coefficients. 


\begin{tabular}{|c|c|c|c|}
\hline \multicolumn{4}{|l|}{ Table 6.} \\
\hline Paths & B & p-value & $95 \% \mathrm{CI}$ \\
\hline $\begin{array}{l}\text { Path } a: \text { LHED } \rightarrow \text { problems with } \\
\text { Romantic partner due to alcohol }\end{array}$ & 0.21 & 0.00 & 0.12 to 0.30 \\
\hline $\begin{array}{l}\text { Path } b: \text { LHED } \rightarrow \text { problems with } \\
\text { school due to alcohol }\end{array}$ & 0.06 & 0.02 & 0.01 to 0.12 \\
\hline $\begin{array}{l}\text { Path } c: \text { LHED } \rightarrow \text { problems with } \\
\text { peers due to alcohol }\end{array}$ & 0.05 & 0.05 & 0.001 to 0.09 \\
\hline $\begin{array}{l}\text { Path } d: \text { LHED } \rightarrow \text { problems with } \\
\text { parents due to alcohol }\end{array}$ & 0.25 & 0.00 & 0.15 to 0.36 \\
\hline $\begin{array}{l}\text { Path } e: \text { LHED } \rightarrow \text { educational } \\
\text { Attainment }\end{array}$ & -0.02 & 0.917 & -0.05 to 0.04 \\
\hline $\begin{array}{l}\text { Path } f: \text { Problems with romantic } \\
\text { partner due to alcohol } \rightarrow \text { educational } \\
\text { attainment }\end{array}$ & 0.008 & 0.89 & -0.10 to 0.11 \\
\hline $\begin{array}{l}\text { Path } g: \text { Problems with school due to } \\
\text { alcohol } \rightarrow \text { educational attainment }\end{array}$ & -0.02 & -0.26 & -0.21 to 0.22 \\
\hline $\begin{array}{l}\text { Path } h \text { : Problems with peers due to } \\
\text { alcohol } \rightarrow \text { educational attainment }\end{array}$ & 0.05 & 0.64 & -0.16 to 0.26 \\
\hline $\begin{array}{l}\text { Path } i \text { : Problems with parents due to } \\
\text { alcohol } \rightarrow \text { educational attainment }\end{array}$ & 0.05 & 0.74 & -0.08 to 0.18 \\
\hline
\end{tabular}

Note. B signifies unstandardized path coefficients. 


\begin{tabular}{lc}
\hline Table 7. & \\
Summary of drinking variables for $7^{\text {th }}$ and $8^{\text {th }}$ graders $(N=3531)$ \\
\hline Variable & n (unweighted \%) \\
\hline Number of days drunk in the past year & $3069(86.9 \%)$ \\
None & $212(6.0 \%)$ \\
1 or 2 days & $74(2.1 \%)$ \\
Once a month or less $(3$ to 12 & \\
times) & $72(2.0 \%)$ \\
2 or 3 days a month & $51(1.4 \%)$ \\
1 or 2 days a week & $31(1.0 \%)$ \\
3 to 5 days a week & $11(.3 \%)$ \\
Every day or almost every day & $5(.1 \%)$ \\
Not reported & \\
Number of days in the past year with & \\
five drinks in a row & $3086(87.4 \%)$ \\
None & $168(4.8 \%)$ \\
1 or 2 days & $84(2.4 \%)$ \\
Once a month or less (3 to 12 & \\
times) & $73(2.1 \%)$ \\
2 or 3 days a month & $56(1.6 \%)$ \\
1 or 2 days a week & $40(1.1 \%)$ \\
3 to 5 days a week & $20(.6)$ \\
Every day or almost every day & $4(.1 \%)$ \\
Not reported &
\end{tabular}


Table 8.

Summary of drinking variables for $12^{\text {th }}$ graders $(n=679)$

\begin{tabular}{lc}
\hline Variable & $\mathrm{n}$ (unweighted $\%)$ \\
\hline Number of days drunk in the past year & $401(59.1 \%)$ \\
None & $107(15.8 \%)$ \\
1 or 2 days & $44(6.5 \%)$ \\
Once a month or less (3 to 12 & \\
times) & $56(8.2 \%)$ \\
2 or 3 days a month & $50(7.4 \%)$ \\
1 or 2 days a week & $11(1.6 \%)$ \\
3 to 5 days a week & $9(1.3 \%)$ \\
Every day or almost every day & $1(.1 \%)$ \\
Not reported & \\
Number of days in the past year with & \\
five drinks in a row & $422(62.2 \%)$ \\
None & $77(11.3 \%)$ \\
1 or 2 days & $44(6.5 \%)$ \\
Once a month or less (3 to 12 & \\
times) & $60(8.8 \%)$ \\
2 or 3 days a month & $43(6.3 \%)$ \\
1 or 2 days a week & $22(3.2 \%)$ \\
3 to 5 days a week & $10(1.5)$ \\
Every day or almost every day & $1(.1 \%)$ \\
Not reported & \\
\hline
\end{tabular}


Figure 2. Unstandardized path coefficients for Seventh and Eighth graders.

Wave 1

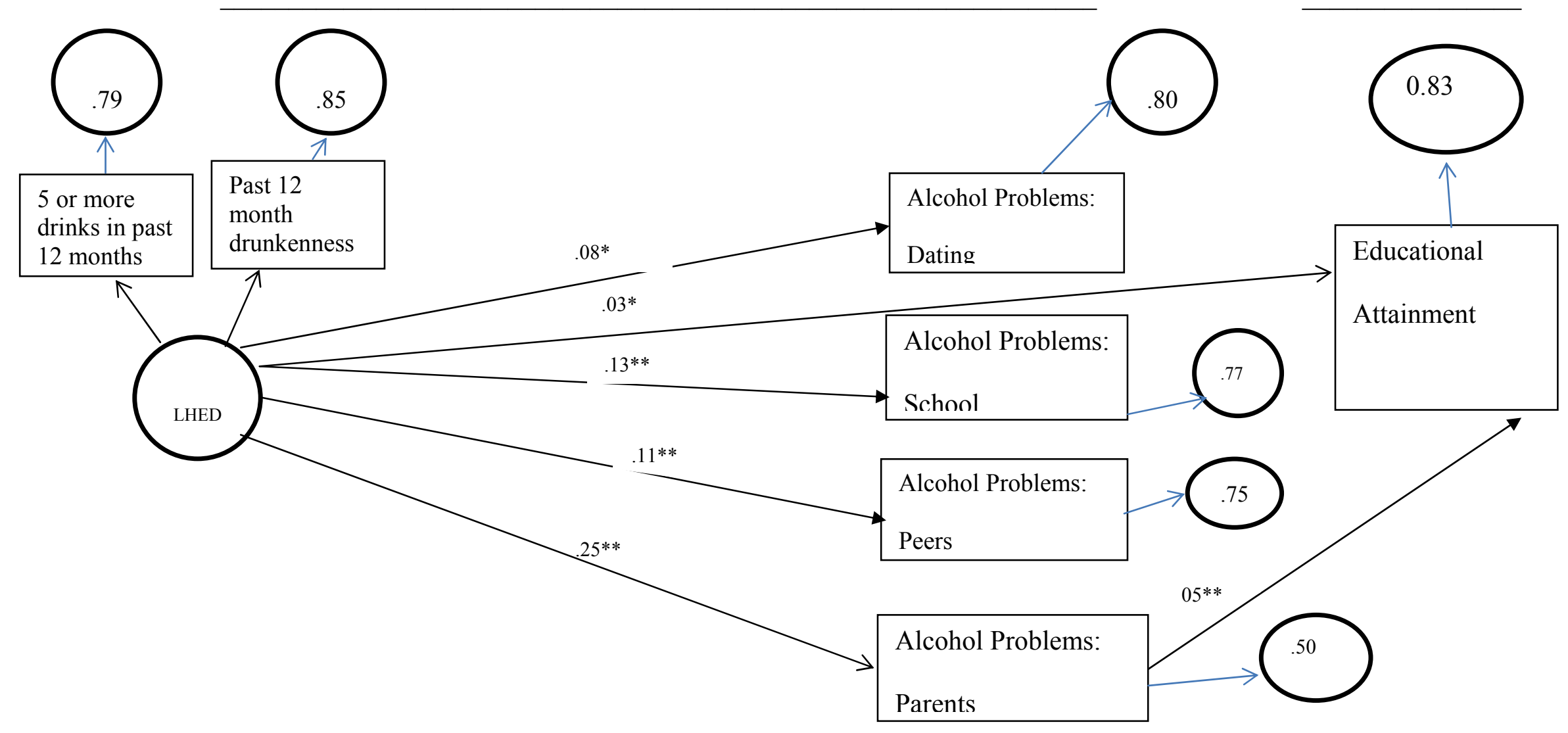


Note. ${ }^{*} p<0.5,{ }^{* *} p<.01$. Only significant paths shown in the figure. All analyses included measures of educational attainment of parent, student's educational aspirations, parental income, and if the father lived in the home as covariates for all endogenous variables. 
Figure 3. Unstandardized path coefficients for $12^{\text {th }}$ graders.

Wave 1

Wave 3

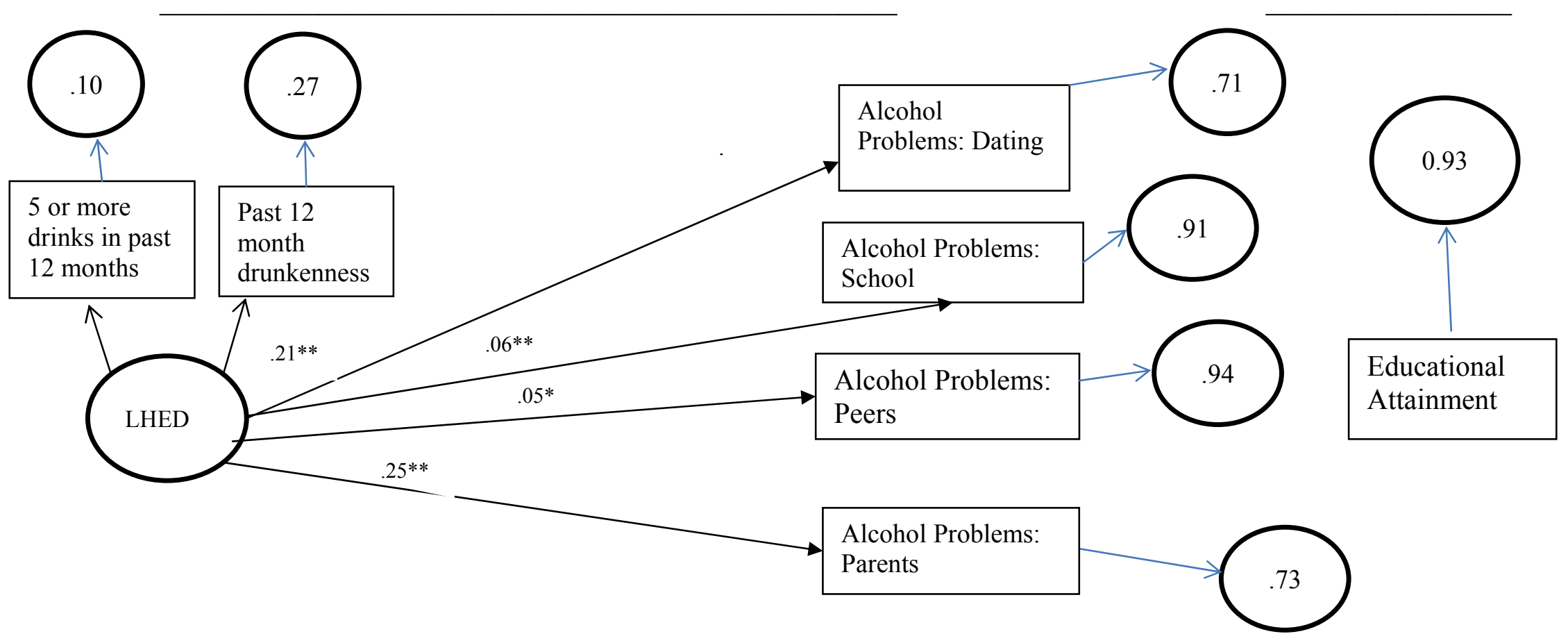


Note. ${ }^{*} p<0.5,{ }^{* *} p<.01$. All analyses included measures of educational attainment of parent, student's educational aspirations, parental income, and if the father lived in the home as covariates for all endogenous variables. 
VITA

\section{TRACEY ANNE GARCIA}

$\begin{array}{ll}\text { September 12, } 1983 & \text { Born, Miami, FL } \\ 2002-2005 & \begin{array}{l}\text { B.A., Psychology } \\ \text { Florida International University } \\ \text { Miami, FL }\end{array} \\ & \begin{array}{l}\text { M.S., Psychology } \\ \text { Florida International University } \\ \text { Miami, Florida }\end{array} \\ 2005-2009 & \begin{array}{l}\text { Doctoral Candidate, Psychology } \\ \text { Florida International University } \\ \text { Miami, Florida }\end{array}\end{array}$

\section{PUBLICATIONS AND PRESENTATIONS}

Garcia, T.A., Benavides, D., Crook, B.C. (2006, March). Social Anxiety, Gender, and Alcohol Use: The Relations among Hispanic Young Adults. Poster Session at the Anxiety Disorders Association of America's 26th Annual Conference.

Garcia, T. A., Ham, L. S., \& Boveda, I. (2007, November). Context and the Relationship between Social Anxiety and the Urge to Drink. Poster to be presented at the $41^{\text {st }}$ annual meeting of the Association for Behavior and Cognitive Therapies, Philadelphia, PA.

Garcia, T.A., Ham, L.S., Montgomery, M.J., Hernandez, L. (2006, March). An Initial Examination of the Role of Gender in Social Anxiety and Self-Medication. Poster Session at the Anxiety Disorders Association of America's 26th Annual Conference.

[Poster also digested in Primary Psychiatry, 13(6), 14-18.]

Garcia, T. A., Ham, L. S., \& Crook, B. C., (2006, November). An Initial Examination of Social Anxiety and Marijuana Use among College Students. Poster to be presented at the $40^{\text {th }}$ annual meeting of the Association for Cognitive Behavioral Therapy, Chicago, IL

Garcia, T. A., Mendez, S. A., Ham, L. S., Hospital, M., \& Zamboanga, B. L. (2009, November). Liquid courage alcohol expectancies partially mediates the relationship between social anxiety and drinking game participation. Poster presented at the annual meeting of the Association for Behavior and Cognitive Therapies, New York, NY. 
Garcia, T. A., Rey, Y., Zamora, N., \& Ham, L. S., (2007). Examination of Social Anxiety and Cannabis Use among College Students- An extension. Poster presented at the 115th American Psychological Association Conference in San Francisco, CA.

Ham, L. S., \& Garcia, T. A. (2010). Assessment of social skills in substance use disorders. In D. W. Nangle, C. A. Erdley, D. J. Hansen, \& P. J. Norton (Eds.), Practitioner's Guide to Empirically-Based Measures of Social Skills (AABT Clinical Assessment Series) (pp. 225-249). New York: Springer.

Ham, L. S., Garcia, T. A., \& Surace, F. I. (2007, November). Social anxiety and hazardous alcohol use among college students: The role of coping and conformity drinking motives. In L. S. Ham (Chair), Drinking to cope with anxiety: Understanding the mechanisms and clinical implications for college students. Symposium to be conducted at the $41^{\mathrm{st}}$ annual meeting of the Association for Behavior and Cognitive Therapies, Philadelphia, PA.

Ham, L. S., Garcia, T. A., \& Surace, F. I. (2007, November). Social anxiety and hazardous alcohol use among college students: The role of coping and conformity drinking motives. Poster to be presented at the $41^{\text {st }}$ annual meeting of the Association for Behavior and Cognitive Therapies, Philadelphia, PA.

Ham, L. S., Zamboanga, B. L., Bacon, A. K., \& Garcia, T. A. (2009). Drinking motives as mediators of social anxiety and hazardous drinking among college students. Cognitive Behaviour Therapy.

Schreiber Compo, N., Evans, J.R., Carol, R., Villalba, D., Ham, L., Garcia, T. \& Rose, S. (in press). Intoxicated witnesses: Better than their reputation? Law and Human Behavior

Zamboanga, B. L., O'Riordan, S.S.,McCollum, E. C., Calvert, B. D., Garcia, T. A., Jarvis, L. H., Ham, L. S., \& Schwartz, S. J., (2006). I Think Therefore I Drink? Drinking Expectancies and Alcohol Experimentation among Early Adolescents. Poster presented to Society for Research on Child Developmen 